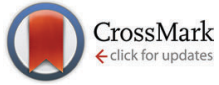

Cite this: J. Mater. Chem. C, 2016 , 4, 8758

Received 23rd June 2016, Accepted 23rd August 2016

DOI: 10.1039/c6tc02601j

www.rsc.org/MaterialsC

\title{
Diacenopentalene dicarboximides as new $n$-type organic semiconductors for field-effect transistors $\dagger$
}

\author{
Gaole Dai, ${ }^{\star a}$ Jingjing Chang, ${ }^{b}$ Linzhi Jing $^{\mathrm{b}}$ and Chunyan Chi ${ }^{\mathrm{b}}$
}

\begin{abstract}
$N, N^{\prime}$-Dihexyl-dibenzopentalene dicarboximide (DBPDI) and $N, N^{\prime}$-dioctyl-dinaphthopentalene dicarboximide (DNPDI) were successfully synthesized as new $n$-type semiconducting materials. They have good solubility in common organic solvents. DBPDI and DNPDI are thermally stable, with decomposition temperatures at 419 and $460{ }^{\circ} \mathrm{C}$, respectively, based on thermogravimetric analysis, and melt at 354 and $387^{\circ} \mathrm{C}$ as measured by differential scanning calorimetry. Their optical and electrochemical properties were studied by UV-vis absorption and cyclic voltammetry measurements. Time-dependent density functional theory calculations (TDDFT) were used to explain their unique electronic absorption spectra. DBPDI and DNPDI have relatively low-lying LUMO energy levels at $-3.76 \mathrm{eV}$ and $-3.45 \mathrm{eV}$ and HOMO energy levels at $-5.84 \mathrm{eV}$ and $-5.72 \mathrm{eV}$, respectively. Their application in organic field-effect transistors (FETs) was investigated. Both DBPDI and DNPDI showed $n$-type field-effect transistor behavior. The DBPDI device obtained by solution-processing technique displayed an average electron mobility of up to $0.06 \mathrm{~cm}^{2} \mathrm{~V}^{-1} \mathrm{~s}^{-1}$ with an $I_{\text {on }} / I_{\text {off }}$ ratio of $2.9 \times 10^{6}$.
\end{abstract}

\section{Introduction}

In the last decade, interest in the synthesis of cyclic $\pi$-conjugated systems incorporated with an antiaromatic unit has increased. Pentalene, as one of the important antiaromatic systems, has attracted much attention. ${ }^{1}$ Parent pentalene, with its $8 \pi$ electron framework, is unstable and easily dimerizes above $-196{ }^{\circ} \mathrm{C}$. Dibenzopentalene (DBP) has been synthesized by different methods, and it is a fairly stable compound with a planar structure and $4 \mathrm{n} \pi$ electron periphery. ${ }^{2}$ Incorporation of the antiaromatic pentalene unit into the acene framework is expected to be an efficient approach to stabilizing the acene moieties due to the intramolecular donor-acceptor interactions. As expected, the extended dinaphthopentalene (DNP) ${ }^{2 o, q, 3}$ and dianthracenopentalene (DAP $)^{4}$ derivatives were reported, and they can be used as p-type organic semiconductors with good stability. Other pentalene-containing molecules have also been studied for their applications in organic electronics. ${ }^{5}$ The pentalene unit can be regarded as a weak electron-withdrawing moiety that can stabilize the electron-rich moieties such as acenes but

\footnotetext{
${ }^{a}$ Functional Nano \& Soft Materials Laboratory (FUNSOM) and Collaborative Innovation Center of Suzhou Nano Science and Technology, Jiangsu Key Laboratory for Carbon-Based Functional Materials \& Devices, Soochow University, Suzhou, Jiangsu, P. R. China. E-mail: daigaole@suda.edu.cn

${ }^{b}$ Department of Chemistry, National University of Singapore, 3 Science Drive 3, 117543, Singapore.E-mail: chmcc@nus.edu.sg

$\dagger$ Electronic supplementary information (ESI) available. See DOI: 10.1039/c6tc02601j
}

cannot convert them into n-type materials such as DNP, ${ }^{3} \mathrm{DAP},{ }^{4}$ DBP-based polymers, ${ }^{5 a}$ pyrrole-fused $\mathrm{DBP},{ }^{5 c}$ and thienoacenefused pentalenes, ${ }^{5 d}$ which all show hole transport properties. To prepare n-type pentalene derivatives, other electron-deficient groups need to be incorporated. For example, dibenzo[a,e]pentalene-embedded thienoquinoidals with dicyanomethylene termini were prepared in 2015 by Takimiya's group. ${ }^{5 b}$ They have low-lying LUMO energy levels $(-4.2$ to $-4.3 \mathrm{eV})$ and showed n-type field-effect transistor (FET) behaviour. Under ambient conditions, the devices produced by solution-processing technique showed electron mobility of up to $4.5 \times 10^{-2} \mathrm{~cm}^{2} \mathrm{~V}^{-1} \mathrm{~s}^{-1}$. Besides this work, to the best of our knowledge, no more n-type pentalene-based materials have been reported.

Generally, to obtain the electron-transporting materials, the electron-deficient imide group is used to lower the energy level and stabilize the radical anions. Therefore, aromatic diimides such as pyromellitic diimide, ${ }^{6}$ naphthalene diimides, ${ }^{7}$ perylene diimides, ${ }^{8}$ longer acene diimide ${ }^{9-12}$ and large ovalene diimide ${ }^{13}$ were reported to exhibit relatively low energy levels, high electron mobilities, and excellent chemical and thermal stabilities. Following the above design strategies, we expect that incorporation of the imide groups into the diacenopentalene framework would result in new electron-transporting materials with lowlying LUMO energy levels. In this context, two diacenopentalene dicarboximides (DBPDI and DNPDI, Scheme 1) were synthesized, and their performance in organic field-effect transistors (OFETs) was evaluated. Both compounds showed n-type FET behaviour with moderate electron mobilities. 
$\underset{37 \%}{\stackrel{a}{C}}$

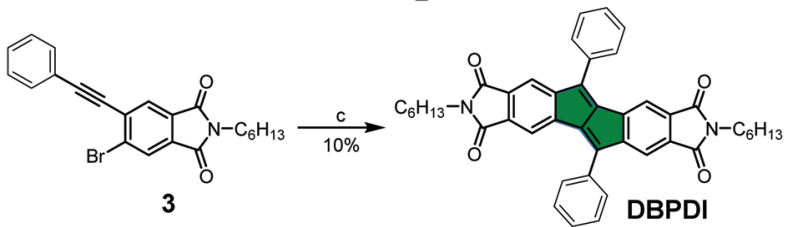

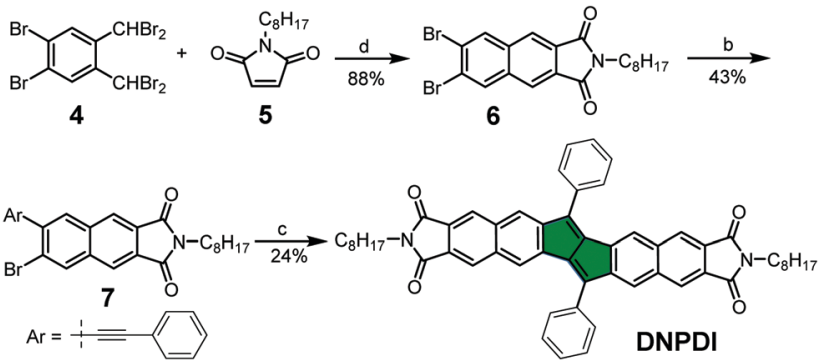

Scheme 1 Reagents and conditions: (a) 1. $\mathrm{SOCl}_{2}, \mathrm{DCM}$; 2. $\mathrm{C}_{6} \mathrm{H}_{13} \mathrm{NH}_{2}$ $\mathrm{AcOH}$, reflux, $12 \mathrm{~h}$; (b) phenylacetylene, $\mathrm{PdCl}_{2}\left(\mathrm{PPh}_{3}\right)_{2}, \mathrm{Cul}, \mathrm{Et}_{3} \mathrm{~N}, \mathrm{THF}$, $75{ }^{\circ} \mathrm{C}$; (c) $\mathrm{Pd}_{2}(\mathrm{dba})_{3}, \mathrm{P}(2 \text {-furyl) })_{3}, \mathrm{Cs}_{2} \mathrm{CO}_{3}, \mathrm{CsF}$, hydroquinone, 1,4-dioxane, $135{ }^{\circ} \mathrm{C}$; (d) Nal, DMF, $80{ }^{\circ} \mathrm{C}, 12 \mathrm{~h}$; DCM: dichloromethane, THF: tetrahydrofuran, dba: dibenzylideneacetone, DMF: N,N-dimethylformamide.

\section{Results and discussion}

\section{Synthesis}

The synthetic route of compounds DBPDI and DNPDI is shown in Scheme 1. Bromination of $o$-xylene and subsequent oxidation of the as-formed 1,2-dibromo-4,5-xylene gave the 4,5-dibromophthalic acid $1 .{ }^{14}$ Compound $\mathbf{1}$ was treated with $\mathrm{SOCl}_{2}$ to give the corresponding acyl chloride. After removing the excess $\mathrm{SOCl}_{2}$, the acyl chloride reacted with hexylamine $\left(\mathrm{C}_{6} \mathrm{H}_{13} \mathrm{NH}_{2}\right)$ in acetic acid under reflux for $12 \mathrm{~h}$ to produce the imide 2 in $37 \%$ yield. In the following step, compound 2 was reacted with phenylacetylene through Sonogashira cross-coupling reaction to give the monosubstituted intermediate 3 in $34 \%$ yield. Eventually, palladium catalysed the cyclodimerization of 3 , providing the target molecule DBPDI in $10 \%$ yield. DNPDI was prepared by starting from 1,2-dibromo-4,5-bis(dibromomethyl)-benzene $4^{15}$ and 1-octyl- $1 H^{-}$ pyrrole-2,5-dione $5 .{ }^{16}$ Compounds 4 and 5 underwent a modified Diels-Alder addition reaction to obtain the intermediate 6 in $88 \%$ yield. $^{9 b}$ Sonogashira cross-coupling reaction between 6 and phenylacetylene gave the mono-substituted compound 7 in $43 \%$ yield, and then similar palladium-catalysed cyclodimerization of 7 produced DNPDI in $24 \%$ yield. Both DBPDI and DNPDI showed good stability and solubility in normal organic solvents (e.g., chloroform, tetrahydrofuran), and their structures were confirmed by NMR and mass spectrometry (see ESI $\dagger$ ).

\section{Optical properties}

The UV-vis absorption spectra of DBPDI and DNPDI were measured in chloroform solution. The spectra are shown in Fig. 1a, and the relevant data are summarized in Table 1. Two broad absorption bands located in the visible region were observed for both compounds. The maximum absorption wavelengths of
DBPDI and DNPDI in the high-energy region are located at 296 and $328 \mathrm{~nm}$, with molar absorption coefficients of 93500 and $88600 \mathrm{M}^{-1} \mathrm{~cm}^{-1}$, respectively. Time-dependent density functional theory (TDDFT) calculations (B3LYP/6-31G*; see Fig. S1, S2 and Tables S1, S2 in ESI $\dagger$ ) indicate that this band originates from a combination of multiple $\mathrm{HOMO}-n \rightarrow$ LUMO $+m$ transitions. The bands in the low-energy region with maxima at 485 and $518 \mathrm{~nm}$ are observed for DBPDI and DNPDI, respectively, and they mainly come from the HOMO-1 $\rightarrow$ LUMO transition (DBPDI: $\lambda=488.2 \mathrm{~nm}$, oscillator strength $f=0.3379$ ) or HOMO $\rightarrow$ LUMO transition (DNPDI: $\lambda=512.3 \mathrm{~nm}$, $f=0.5057)$. The optical energy band gap $\left(E_{\mathrm{g}}^{\text {Opt }}\right)$ of 2.42 and $2.25 \mathrm{eV}$ can be calculated based on the lowest energy of absorption edge in solution (see Table 1). Compared to DBPDI, the absorption maximum of DNPDI in solution is red-shifted $33 \mathrm{~nm}$ due to its more extended $\pi$-conjugation.

\section{Electrochemical properties}

Cyclic voltammetry (CV) and differential pulse voltammetry (DPV) were used to study the electrochemical properties of compounds DBPDI and DNPDI (Fig. 1b, Table 1 and Fig. S3 in ESI $\dagger$ ). The potential was externally calibrated against the ferrocene/ferrocenium couple. Compound DBPDI shows one oxidation wave with half-wave potential $\left(E_{1 / 2}^{\text {ox }}\right)$ of $1.36 \mathrm{~V}$ and two reversible reduction waves with half-wave potentials $E_{1 / 2}^{\text {red }}$ at -1.46 and $-1.11 \mathrm{~V}$. Meanwhile, one oxidation wave with $E_{1 / 2}^{\mathrm{ox}}$ at $1.03 \mathrm{~V}$ and two reversible reduction waves with $E_{1 / 2}^{\mathrm{red}}$ at -1.71 and $-1.47 \mathrm{~V}$ were observed for molecule DNPDI. The HOMO
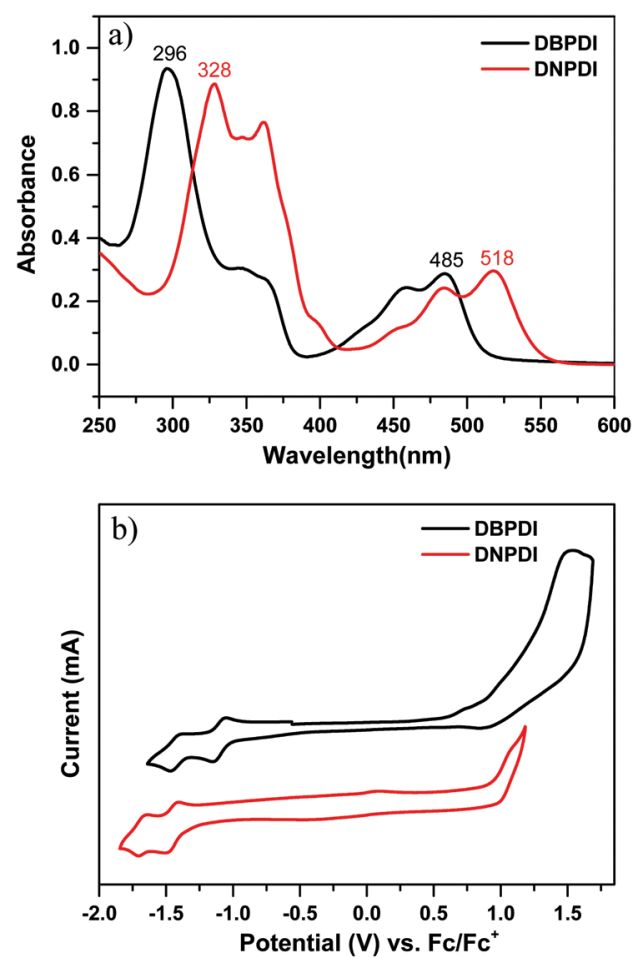

Fig. 1 (a) UV-vis absorption spectra of DBPDI and DNPDI in chloroform $\left(10^{-5} \mathrm{M}\right)$; (b) cyclic voltammograms (CV) of DBPDI and DNPDI measured in dry dichloromethane. 
Table 1 Summary of photophysical properties and electrochemical data of DBPDI and DNPDI

\begin{tabular}{lllllllr}
\hline & $\lambda_{\max }(\mathrm{abs})[\mathrm{nm}]$ in solution & $\log \varepsilon_{\max }\left[\mathrm{M}^{-1} \mathrm{~cm}^{-1}\right]$ & $E_{1 / 2}^{\mathrm{ox}}(\mathrm{V})$ & $E_{1 / 2}^{\mathrm{red}}(\mathrm{V})$ & HOMO $[\mathrm{eV}]$ & $\mathrm{LUMO}[\mathrm{eV}]$ & $E_{\mathrm{g}}^{\mathrm{Opt}}[\mathrm{eV}]$ \\
\hline DBPDI & 296 & 4.97 & 1.36 & $-1.46 ;-1.11$ & -5.84 & -3.76 & 2.42 \\
DNPDI & 328 & 4.95 & 1.03 & $-1.71 ;-1.47$ & -5.72 & -3.45 & 2.25 \\
\hline
\end{tabular}

and LUMO energy levels were calculated using the following equations: $\mathrm{HOMO}=-\left[E_{\mathrm{ox}}^{\text {onset }}+4.8\right] \mathrm{eV}, \mathrm{LUMO}=-\left[E_{\mathrm{red}}^{\mathrm{onset}}+4.8\right] \mathrm{eV}$, where $E_{\mathrm{ox}}^{\text {onset }}$ and $E_{\text {red }}^{\text {onset }}$ are the onset of the first oxidation and reduction wave, respectively. ${ }^{17}$ The HOMO/LUMO energy levels are calculated to be $-5.84 /-3.76 \mathrm{eV}$ for DBPDI and -5.72 / $-3.45 \mathrm{eV}$ for DNPDI. The corresponding electrochemical energy gaps $E_{\mathrm{g}}^{\mathrm{EC}}$ (LUMO-HOMO) are estimated to be $2.08 \mathrm{eV}$ and $2.27 \mathrm{eV}$ for DBPDI and DNPDI, which are close to their optical band gaps $E_{\mathrm{g}}^{\mathrm{Opt}}$.

\section{DFT calculations}

DFT calculations were conducted to better understand the electronic properties of DBPDI and DNPDI (Fig. 2 and Fig. S1, S2 and Tables S1, S2 in ESI $\dagger$ ). The coefficients for HOMO of DBPDI and HOMO-1 of DNPDI are distributed along the diacenopentalene framework, while the phenyl rings are nearly nonconjugated to the backbone. The HOMO-1 of DBPDI and HOMO of DNPDI coefficients are mainly distributed along the zigzag edges of diacenopentane including the phenyl rings. The LUMO coefficient is mainly located on the central pentalene unit and the imide moieties. The HOMO/LUMO energy
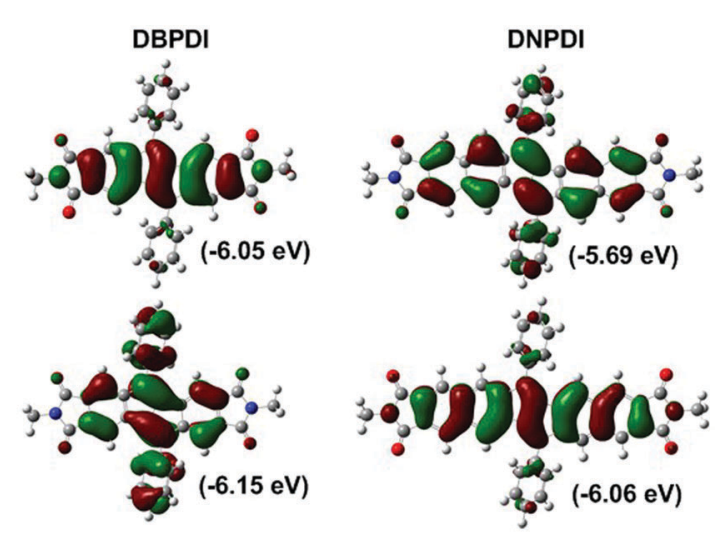

LUMO
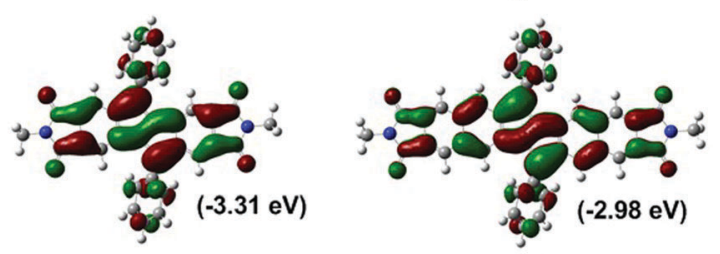

LUMO+1
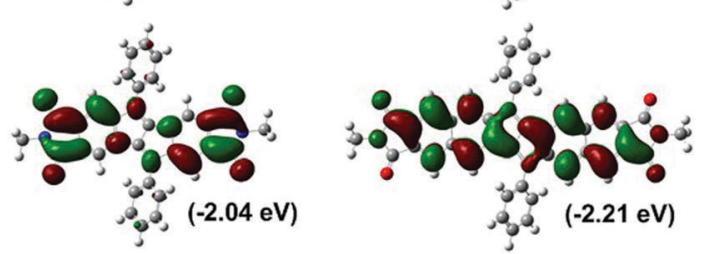

Fig. 2 The calculated HOMO/LUMO profiles and energy levels of DBPDI and DNPDI (B3LYP/6-31G*). levels were calculated to be $-6.05 /-3.31 \mathrm{eV}$ for DBPDI and $-5.69 /-2.98 \mathrm{eV}$ for DNPDI. It is worth noting that the HOMO and HOMO-1 $(-6.15 \mathrm{eV})$ energy levels of DBPDI are quite close. TDDFT calculations predicted the longest wavelength for HOMO-1 $\rightarrow$ LUMO transition at $488.2 \mathrm{~nm}$ for DBPDI and for HOMO $\rightarrow$ LUMO transition at $512.3 \mathrm{~nm}$ for DNPDI (Fig. S1 and $\mathrm{S} 2$ in the ESI $\dagger$ ), which is consistent with the experimental data.

\section{Thermal properties}

Thermal stability is one of the key requirements for the practical application of organic electronic materials. Compounds DBPDI and DNPDI showed good thermal stability, with decomposition temperatures $\left(T_{\mathrm{d}}\right.$, corresponding to a $5 \%$ weight loss in thermogravimetric analysis (TGA) curves) at 419 and $460{ }^{\circ} \mathrm{C}$, respectively (Fig. S4a and c, ESI $\dagger$ ). The melting points of DBPDI and DNPDI were observed at 354 and $387{ }^{\circ} \mathrm{C}$, and the corresponding crystallization temperatures were observed at 337 and $369{ }^{\circ} \mathrm{C}$, respectively, from differential scanning calorimetry (DSC) curves (Fig. S4b and $\mathrm{d}, \mathrm{ESI} \dagger)$.

\section{Organic field effect transistors}

To probe the charge transport properties of compounds DBPDI and DNPDI, we fabricated field-effect transistor (FET) devices for both compounds by solution-processing method. The bottom-gate, top-contact FETs were fabricated on $\mathrm{p}^{+}-\mathrm{Si} / \mathrm{SiO}_{2}$ substrates by spin-coating $1 \mathrm{wt} \%$ chloroform $\left(\mathrm{CHCl}_{3}\right)$ solutions onto 1-octyltrichlorosilane (OTS) or hexamethyldisilazane (HMDS)-treated substrates. ${ }^{18}$ The thin films were then annealed at selected temperatures for $10 \mathrm{~min}$ in a $\mathrm{N}_{2}$ glovebox. Au source/ drain electrodes $(100 \mathrm{~nm})$ were patterned on the organic layer through a shadow mask to produce the devices. The typical transfer and output curves measured in $\mathrm{N}_{2}$ are shown in Fig. 3. Well-defined saturation characteristics were observed for both. The OFET device parameters for the thin films of DBPDI and DNPDI under different conditions measured under nitrogen are summarized in Table 2. The device parameters are averaged based on over 36 devices in two different batches. The devices showed good uniformity and reproducibility.

Both compounds exhibited n-type FET behaviour. For compound DBPDI, the devices revealed an average electron mobility of $4.6 \times 10^{-3} \mathrm{~cm}^{2} \mathrm{~V}^{-1} \mathrm{~s}^{-1}\left(I_{\mathrm{on}} / I_{\text {off }}=10^{6}\right)$ and $0.06 \mathrm{~cm}^{2} \mathrm{~V}^{-1} \mathrm{~s}^{-1}$ $\left(I_{\text {on }} / I_{\text {off }}=10^{6}\right)$ for HMDS- and OTS-treated substrates, respectively. The device based on DNPDI displayed an average saturation mobility of $0.011 \mathrm{~cm}^{2} \mathrm{~V}^{-1} \mathrm{~s}^{-1}\left(I_{\mathrm{on}} / I_{\text {off }}=10^{6}\right)$ and $0.034 \mathrm{~cm}^{2} \mathrm{~V}^{-1} \mathrm{~s}^{-1}$ $\left(I_{\text {on }} / I_{\text {off }}=10^{6}\right)$ for HMDS- and OTS-treated substrates, respectively. The thermal annealing has a lower effect on the charge carrier mobilities, indicating that these two materials are good choices for annealing-free device fabrication in the plastic electronics. The DBPDI showed slightly higher charge carrier mobilities and less 

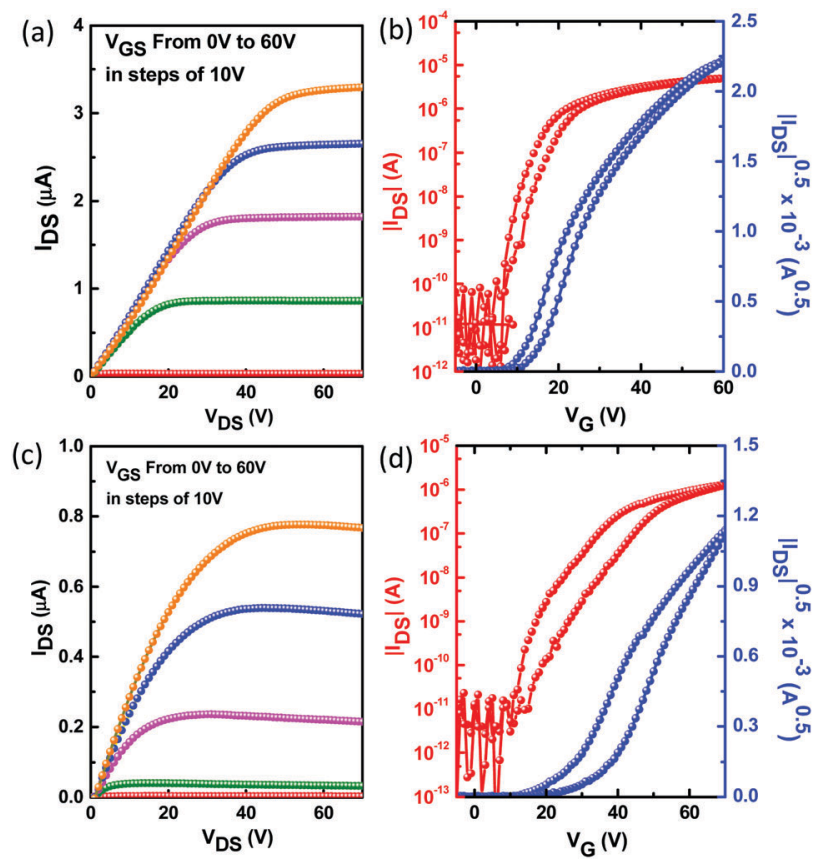

Fig. 3 Output and transfer characteristics of the thin films DBPDI ( $a$ and $b$ ) and DNPDI (c and d) spin-coated on OTS-modified substrates.

Table 2 OFET characteristics of DBPDI- and DNPDI-based devices fabricated on $\mathrm{Si} / \mathrm{SiO}_{2}$ substrates with different surface treatments and different annealing temperatures

\begin{tabular}{llllll}
\hline & $\begin{array}{l}\text { Surface } \\
\text { treatment }\end{array}$ & $\begin{array}{l}\text { Annealing } \\
\text { temp. }\end{array}$ & $\mu\left[\mathrm{cm}^{2} \mathrm{~V}^{-1} \mathrm{~s}^{-1}\right]$ & $V_{\mathrm{T}}[\mathrm{V}]$ & On/off \\
\hline DBPDI & HMDS & XA & $3.0 \times 10^{-3}$ & $2-4$ & $9.6 \times 10^{5}$ \\
& HMDS & A120 & $4.6 \times 10^{-3}$ & $2-4$ & $7.8 \times 10^{5}$ \\
& OTS-C8 & XA & 0.05 & $7-10$ & $2.6 \times 10^{6}$ \\
& OTS-C8 & A120 & 0.06 & $5-8$ & $2.9 \times 10^{6}$ \\
DNPDI & HMDS & XA & $4.7 \times 10^{-3}$ & $28-30$ & $3.2 \times 10^{6}$ \\
& HMDS & A120 & 0.011 & $24-26$ & $2.0 \times 10^{6}$ \\
& HMDS & A160 & $6.8 \times 10^{-3}$ & $23-25$ & $2.1 \times 10^{5}$ \\
& OTS-C8 & XA & 0.025 & $16-18$ & $1.7 \times 10^{6}$ \\
& OTS-C8 & A120 & 0.034 & $15-17$ & $1.1 \times 10^{6}$
\end{tabular}

hysteresis, indicating that less traps exist in the thin film due to better film crystallinity and less grain boundaries, which is explained in the following section. Both DBPDI and DNPDI showed decreased charge carrier mobility when their devices were operated in ambient conditions.

Thin-film morphology and solid-state microstructure were characterized by tapping-mode atomic force microscopy (AFM) and 2D X-ray diffraction (XRD). The thin films exhibited ribbonlike crystals for DBPDI and fibre-like crystals for DNPDI (Fig. 4). The root mean square (RMS) values of surface roughness are $29.1 \mathrm{~nm}$ and $30.3 \mathrm{~nm}$ for DBPDI before and after annealing, respectively. For DNPDI thin film, the RMS values are $7.7 \mathrm{~nm}$ and $8.6 \mathrm{~nm}$ before and after annealing, respectively. The larger surface roughness of DBPDI thin film is ascribed to the larger crystal size, which reduces the grain boundaries. The XRD measurements of the thin films on OTS-treated substrates exhibited primary peaks at $2 \theta=5.8^{\circ}$ and $4.5^{\circ}$, which correspond

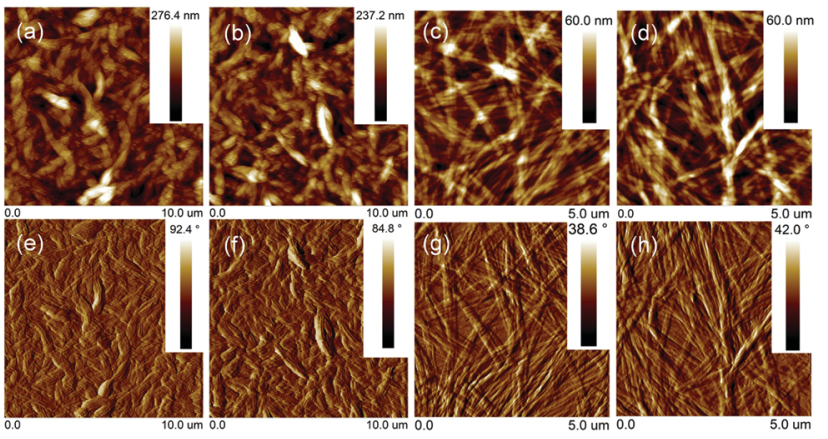

Fig. 4 The AFM images of the thin film spin-coated from $\mathrm{CHCl}_{3}$ solution onto OTS: DBPDI (a: before annealing; b: annealing at $120^{\circ} \mathrm{C}$ ) and DNPDI (c: before annealing; $\mathrm{d}$ : annealing at $120^{\circ} \mathrm{C}$ ); e-h are the corresponding phase images.
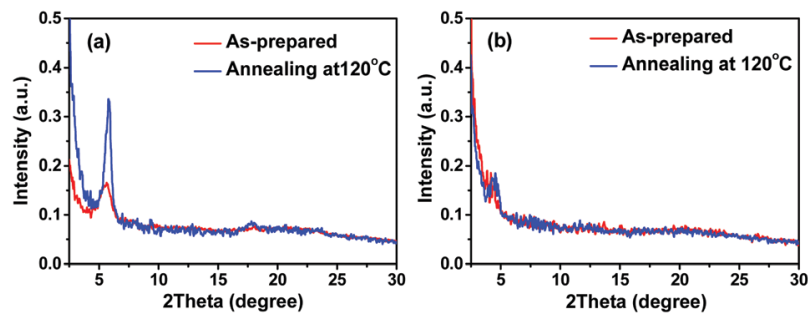

Fig. 5 XRD patterns of DBPDI (a) and DNPDI (b) thin films on OTSmodified substrates.

to $d$-spacing of $15.2 \AA$ and $19.6 \AA$ for DBPDI and DNPDI, respectively (Fig. 5). These are quite close to their molecular lengths of $15.7 \AA$ and $20.6 \AA$, indicating that both of them are packed in a layer-like structure. In addition, the intensity of the diffraction peak of DBPDI is much stronger than that of DNPDI, although they have a similar film thickness $(60$ to $70 \mathrm{~nm})$. The better film crystallinity and larger crystal size of DBPDI thin films ensure a lower amount of traps due to the reduced grain boundaries and give efficient charge transport between the source and drain electrodes.

\section{Conclusion}

In conclusion, two diacenopentalene diimides, DBPDI and DNPDI, have been successfully synthesized as new $\pi$-conjugated organic semiconducting materials for OFETs. They have good solubility in common organic solvents and show high thermal stability, with decomposition temperatures above $400{ }^{\circ} \mathrm{C}$. DBPDI and DNPDI have relatively low-lying LUMO energy levels at -3.76 and $-3.45 \mathrm{eV}$, respectively. Their thin-film transistor test indicated that they are n-type semiconductors. DBPDI and DNPDI devices produced by solution processing technique displayed average electron mobilities of up to $0.06 \mathrm{~cm}^{2} \mathrm{~V}^{-1} \mathrm{~s}^{-1}$ with $I_{\text {on }} / I_{\text {off }}$ ratio of $2.9 \times 10^{6}$ and $0.034 \mathrm{~cm}^{2} \mathrm{~V}^{-1} \mathrm{~s}^{-1}$ with $I_{\text {on }} / I_{\text {off }}$ ratio of $1.1 \times 10^{6}$ in $\mathrm{N}_{2}$, respectively. More effort will be carried out to modify this kind of molecule and optimize fabrication conditions $^{19}$ to improve device performance. 


\section{Experiment section}

\section{Materials}

All reagents were purchased from commercial sources without further purification. Anhydrous dichloromethane (DCM) was distilled from $\mathrm{CaH}_{2}$. 1,4-Dioxane and THF were distilled from sodium-benzophenone immediately prior to use. 4,5-Dibromophthalic acid 1, 1,2-dibromo-4,5-bis(dibromomethyl)benzene 4 and 1 -octyl- $1 H$-pyrrole-2,5-dione $\mathbf{5}$ were prepared by following literature procedures.

\section{General characterization method}

${ }^{1} \mathrm{H}$ and ${ }^{13} \mathrm{C}$ NMR spectra were recorded using an Avance $500 \mathrm{MHz}$ Bruker spectrometer in $\mathrm{CDCl}_{3}$ with tetramethylsilane (TMS) as the internal standard. The chemical shift was recorded in ppm, and the following abbreviations are used to explain the multiplicities: $\mathrm{s}=$ singlet, $\mathrm{d}=$ doublet, $\mathrm{t}=$ triplet, $\mathrm{m}=$ multiplet, $\mathrm{br}=$ broad. Column chromatography was performed on silica gel 60 (Merck 40-60 nm, 230-400 mesh). EI mass spectra were recorded on an Agilent 5975 C DIP/MS mass spectrometer. UV-vis absorption was recorded on a Shimadzu UV-1700 spectrophotometer. Cyclic voltammetry and differential pulse voltammetry measurements were performed in HPLC-grade dry dichloromethane on a CHI 620C electrochemical analyzer with a three-electrode cell, using $0.1 \mathrm{M} \mathrm{Bu}_{4} \mathrm{NPF}_{6}$ as the supporting electrolyte, $\mathrm{AgCl} / \mathrm{Ag}$ as the reference electrode, a gold disk as the working electrode, and Pt wire as the counter electrode, at a scan rate of $50 \mathrm{mV} \mathrm{s}^{-1}$. The potential was externally calibrated against the ferrocene/ferrocenium couple. Differential scanning calorimetry (DSC) was performed on a TA instrument 2920 at a heating/ cooling rate of $10{ }^{\circ} \mathrm{C} \mathrm{min}^{-1}$ under nitrogen flow.

\section{Synthesis}

Compound 2 5,6-dibromo-2-hexylisoindoline-1,3-dione. A mixture of 1 ( $4.0 \mathrm{~g}, 12.35 \mathrm{mmol}$ ) and thionyl chloride $(6 \mathrm{~mL})$ in $30 \mathrm{~mL}$ of dry dichloromethane was stirred overnight at reflux temperature under argon atmosphere. After removing excess thionyl chloride and solvent, the yellowish solid was directly dissolved in $30 \mathrm{~mL}$ of dry acetic acid and used in the next reaction. The hexyl amine $(1.3 \mathrm{~g}, 13.58 \mathrm{mmol})$ was slowly added, and the mixture was heated to $135{ }^{\circ} \mathrm{C}$ overnight under argon. The mixture was cooled to room temperature and extracted with EtAc $(80 \mathrm{~mL} \times 2)$. The combined organic phase was washed with brine $(100 \mathrm{~mL} \times 2)$ and saturated $\mathrm{NaHCO}_{3}$ solution $(100 \mathrm{~mL})$ and dried over anhydrous $\mathrm{Na}_{2} \mathrm{SO}_{4}$. The organic solvent was removed under reduced pressure, and the residue was purified by column chromatography (silica gel, DCM/hexane $=1: 5$ ) to afford compound $2(1.75 \mathrm{~g})$ in $37 \%$ yield. ${ }^{1} \mathrm{H}$ NMR $\left(500 \mathrm{MHz}, \mathrm{CDCl}_{3}, \mathrm{ppm}\right)$ $\delta=8.07(\mathrm{~s}, 2 \mathrm{H}), 3.66(\mathrm{t}, J=7.5 \mathrm{~Hz}, 2 \mathrm{H}), 1.68-1.60(\mathrm{~m}, 2 \mathrm{H}), 1.33-$ $1.25(\mathrm{~m}, 6 \mathrm{H}), 0.87(\mathrm{t}, J=6.8 \mathrm{~Hz}, 3 \mathrm{H}) .{ }^{13} \mathrm{C} \mathrm{NMR}\left(\mathrm{CDCl}_{3}, 125 \mathrm{MHz}\right)$ : $\delta=166.47,131.87,131.23,128.33,38.52,31.28,28.37,26.46$, 22.47, 13.95. HR MS (EI): calcd for $\mathrm{C}_{14} \mathrm{H}_{15} \mathrm{Br}_{2} \mathrm{NO}_{2}\left(\mathrm{M}^{+}\right), 386.9470$; found, 386.9458 (error: $-3.10 \mathrm{ppm}$ ).

Compound 3 5-bromo-2-hexyl-6-(phenylethynyl)isoindoline1,3-dione. A suspension of $\mathrm{Pd}\left(\mathrm{PPh}_{3}\right)_{2} \mathrm{Cl}_{2}$ (135 mg, $\left.5 \mathrm{~mol} \%\right)$, $\mathrm{CuI}$ (36 mg, $5 \mathrm{~mol} \%)$ and $2(1.50 \mathrm{~g}, 3.88 \mathrm{mmol})$ were purged with argon. After dissolving the mixture with $20 \mathrm{~mL}$ of tetrahydrofuran (THF) and $20 \mathrm{~mL}$ of anhydrous triethylamine $\left(\mathrm{Et}_{3} \mathrm{~N}\right)$, phenyl acetylene $(0.435 \mathrm{~g}, 4.26 \mathrm{mmol})$ was slowly added to the solution, then the mixture was stirred at $75{ }^{\circ} \mathrm{C}$ overnight. After cooling down to room temperature, the mixture was poured into EtOAc $(60 \mathrm{~mL} \times 2)$ and washed with $10 \%$ hydrochloride solution $(60 \mathrm{~mL} \times 2)$. The organic layer was dried on $\mathrm{Na}_{2} \mathrm{SO}_{4}$ and concentrated under vacuum. Finally, the residue was purified carefully by column chromatography (silica gel, DCM/ hexane $=1: 10)$ to give compound $3(530 \mathrm{mg})$ in $34 \%$ yield. ${ }^{1} \mathrm{H}$ NMR (500 MHz, $\left.\mathrm{CDCl}_{3}, \mathrm{ppm}\right) \delta=8.07$ (s, 1H), $7.97(\mathrm{~s}, 1 \mathrm{H})$, $7.63-7.59(\mathrm{~m}, 2 \mathrm{H}), 7.43-7.38(\mathrm{~m}, 3 \mathrm{H}), 3.67(\mathrm{t}, J=7.3 \mathrm{~Hz}, 2 \mathrm{H})$, 1.70-1.62 (m, 2H), 1.34-1.25 (m, 6H), $0.88(\mathrm{t}, J=7.0 \mathrm{~Hz}, 3 \mathrm{H}) .{ }^{13} \mathrm{C}$ NMR $\left(\mathrm{CDCl}_{3}, 125 \mathrm{MHz}\right): \delta=167.15,166.69,131.96,131.63$, 131.58, 131.07, 130.82, 129.57, 128.56, 127.34, 127.26, 121.92, 98.69, 87.20, 38.44, 31.31, 28.44, 26.49, 22.48, 13.95. HR MS (EI): calcd for $\mathrm{C}_{22} \mathrm{H}_{20} \mathrm{BrNO}_{2}\left(\mathrm{M}^{+}\right), 409.0677$; found, 409.0669 (error: $-1.96 \mathrm{ppm}$ ).

Compound DBPDI. A reaction flask was charged with hydroquinone (0.113 g, $1.20 \mathrm{mmol}), \mathrm{Cs}_{2} \mathrm{CO}_{3}(0.334 \mathrm{~g}, 1.02 \mathrm{mmol}), \mathrm{CsF}$ (0.171 g, $1.13 \mathrm{mmol}), \mathrm{P}(2 \text {-furyl })_{3}(15 \mathrm{mg}, 0.08 \mathrm{mmol})$, and $\mathrm{Pd}_{2}(\mathrm{dba})_{3}(15 \mathrm{mg}, 0.02 \mathrm{mmol})$ and purged with argon. A solution of $3(0.200 \mathrm{~g}, 0.50 \mathrm{mmol})$ in 1,4-dioxane $(15 \mathrm{~mL})$ was injected into the catalyst mixture with a syringe. The suspension was immediately heated to $135^{\circ} \mathrm{C}$. After heating for $24 \mathrm{~h}$, the reaction mixture was diluted with $\mathrm{CH}_{2} \mathrm{Cl}_{2}(20 \mathrm{~mL})$, filtered through celite, and then concentrated to yield raw solid. After purification via column chromatography (silica gel, DCM/hexane $=1: 4$ ), the product was dissolved in $\mathrm{CHCl}_{3}$, precipitated in methanol/ acetone $=3: 2$ and filtered. This procedure was repeated three times to give the purer product DBPDI (12 mg) in $10 \%$ yield for characterization. ${ }^{1} \mathrm{H}$ NMR (500 $\left.\mathrm{MHz}, \mathrm{CDCl}_{3}, \mathrm{ppm}\right) \delta=7.65-7.57$ (m, 10H), 7.56 (s, 2H), 7.49 (s, 2H), 3.61 (t, $J=7.3 \mathrm{~Hz}, 4 \mathrm{H}), 1.66-$ $1.58(\mathrm{~m}, 4 \mathrm{H}), 1.29-1.25(\mathrm{~m}, 12 \mathrm{H}), 0.86(\mathrm{t}, J=6.8 \mathrm{~Hz}, 6 \mathrm{H}) .{ }^{13} \mathrm{C} \mathrm{NMR}$ $\left(\mathrm{CDCl}_{3}, 125 \mathrm{MHz}\right): \delta=168.17,168.05,154.70,143.98,143.44$, $140.43,132.51,132.45,131.77,130.42,129.47,128.31,117.70$, 116.41, 38.11, 31.34, 28.50, 26.46, 22.48, 13.98. HR MS (EI): calcd for $\mathrm{C}_{44} \mathrm{H}_{40} \mathrm{~N}_{2} \mathrm{O}_{4}\left(\mathrm{M}^{+}\right), 660.2988$; found, 660.2994 (error: $0.91 \mathrm{ppm}$ ).

Compound 6 6,7-dibromo-2-octyl-1H-benzo[f]isoindole-1,3(2H)dione. $\mathrm{NaI}(1.55 \mathrm{~g}, 10.5 \mathrm{mmol})$ was added with stirring to a solution of $4(1.20 \mathrm{~g}, 2.1 \mathrm{mmol})$ and $N$-octylmaleimide 5 (0.50 g, $2.39 \mathrm{mmol})$ in $N, N$-dimethylacetamide $(20 \mathrm{~mL})$. The mixture was heated at $80{ }^{\circ} \mathrm{C}$ for $12 \mathrm{~h}$. The product was collected from the dark solution by filtration and washed with water, methanol and acetone. The residue was purified by flash column chromatography (silica gel, DCM/hexane $=1: 1$ ) to provide compound $6(0.85 \mathrm{~g})$ in $88 \%$ yield. ${ }^{1} \mathrm{H}$ NMR (500 MHz, $\left.\mathrm{CDCl}_{3}, \mathrm{ppm}\right) \delta=8.33(\mathrm{~s}, 2 \mathrm{H}), 8.20$ $(\mathrm{s}, 2 \mathrm{H}), 3.74(\mathrm{t}, J=7.5 \mathrm{~Hz}, 2 \mathrm{H}), 1.73-1.68(\mathrm{~m}, 2 \mathrm{H}), 1.37-1.20$ $(\mathrm{m}, 10 \mathrm{H}), 0.86$ (t, $J=7.0 \mathrm{~Hz}, 3 \mathrm{H}) .{ }^{13} \mathrm{C} \mathrm{NMR}\left(\mathrm{CDCl}_{3}, 125 \mathrm{MHz}\right)$ : $\delta=167.36,134.78,134.18,129.12,126.15,123.27,38.55,31.75$, 29.13, 28.47, 26.90, 22.60, 14.04. HR MS (EI): calcd for $\mathrm{C}_{20} \mathrm{H}_{21} \mathrm{Br}_{2} \mathrm{NO}_{2}\left(\mathrm{M}^{+}\right)$, 464.9939; found, 464.9951 (error: $2.58 \mathrm{ppm}$ ).

Compound 7 6-bromo-2-octyl-7-(phenylethynyl)-1H-benzo[f]isoindole-1,3(2H)-dione. A suspension of $\mathrm{Pd}\left(\mathrm{PPh}_{3}\right)_{2} \mathrm{Cl}_{2}(65 \mathrm{mg}$, $5 \mathrm{~mol} \%$ ), CuI (15 mg, $5 \mathrm{~mol} \%$ ) and 6 (850 mg, $1.8 \mathrm{mmol}$ ) was purged with argon. Dissolving the mixture with $15 \mathrm{~mL}$ of 
anhydrous tetrahydrofuran (THF) and $15 \mathrm{~mL}$ anhydrous triethylamine $\left(\mathrm{Et}_{3} \mathrm{~N}\right)$, phenyl acetylene $(180 \mathrm{mg}, 1.8 \mathrm{mmol})$ was slowly added to the solution, then the mixture was stirred at $75{ }^{\circ} \mathrm{C}$ overnight. After cooling down to room temperature, the mixture was poured into EtOAc $(100 \mathrm{~mL})$ and extracted with diluted hydrochloride $(60 \mathrm{~mL} \times 3)$. The organic layer was dried on $\mathrm{Na}_{2} \mathrm{SO}_{4}$ and concentrated under vacuum. Finally, the residue was purified carefully by column chromatography (silica gel, $\mathrm{DCM} /$ hexane $=1: 10$ ) to give compound 7 (380 mg) in $43 \%$ yield. ${ }^{1} \mathrm{H} \mathrm{NMR}\left(500 \mathrm{MHz}, \mathrm{CDCl}_{3}, \mathrm{ppm}\right) \delta=8.32(\mathrm{~s}, 1 \mathrm{H}), 8.26(\mathrm{~s}, 1 \mathrm{H})$, $8.24(\mathrm{~s}, 1 \mathrm{H}), 8.21(\mathrm{~s}, 1 \mathrm{H}), 7.66-7.62(\mathrm{~m}, 2 \mathrm{H}), 7.43-7.40(\mathrm{~m}, 3 \mathrm{H})$, $3.74(\mathrm{t}, J=7.5 \mathrm{~Hz}, 2 \mathrm{H}), 1.74-1.67(\mathrm{~m}, 2 \mathrm{H}), 1.40-1.20(\mathrm{~m}, 10 \mathrm{H})$, $0.87(\mathrm{t}, J=6.8 \mathrm{~Hz}, 3 \mathrm{H}) .{ }^{13} \mathrm{C} \mathrm{NMR}\left(\mathrm{CDCl}_{3}, 125 \mathrm{MHz}\right): \delta=167.58$, $167.49,135.25,134.28,133.79,133.16,131.88,129.24,129.22$, $128.82,128.52,126.37,125.95,123.94,123.19,122.30$, 96.38, $87.42,38.50,31.76,29.14,28.50,26.91,22.61,14.05$. HR MS (EI): calcd for $\mathrm{C}_{28} \mathrm{H}_{26} \mathrm{BrNO}_{2}\left(\mathrm{M}^{+}\right), 487.1147$; found, 487.1136 (error: $-2.26 \mathrm{ppm}$ ).

Compound DNPDI. A reaction flask was charged with hydroquinone (0.172 g, $1.83 \mathrm{mmol}), \mathrm{Cs}_{2} \mathrm{CO}_{3}(0.508 \mathrm{~g}, 1.55 \mathrm{mmol})$, CsF (0.260 g, $1.72 \mathrm{mmol}), \mathrm{P}(2 \text {-furyl })_{3}(23 \mathrm{mg}, 0.12 \mathrm{mmol})$, and $\mathrm{Pd}_{2}(\mathrm{dba})_{3}(23 \mathrm{mg}, 0.026 \mathrm{mmol})$ and purged with argon. A solution of 7 ( $0.372 \mathrm{~g}, 0.76 \mathrm{mmol})$ in 1,4-dioxane $(20 \mathrm{~mL})$ was injected into the catalyst mixture with a syringe. The suspension was immediately heated to $135{ }^{\circ} \mathrm{C}$. After heating for $24 \mathrm{~h}$, the reaction mixture was diluted with $\mathrm{CH}_{2} \mathrm{Cl}_{2}(25 \mathrm{~mL})$, filtered through celite, and then concentrated under vacuum to yield raw solid. After purification via column chromatography (silica gel, DCM $/$ hexane $=1: 4$ ), the product was dissolved in $\mathrm{CHCl}_{3}$, precipitated in methanol/ acetone $=3: 2$ and filtered. This procedure was repeated three times to give the purer product DNPDI (75 mg) in $24 \%$ yield for characterization. ${ }^{1} \mathrm{H} \mathrm{NMR}\left(500 \mathrm{MHz}, \mathrm{CDCl}_{3}, \mathrm{ppm}\right) \delta=8.08(\mathrm{~s}, 2 \mathrm{H})$, $8.05(\mathrm{~s}, 2 \mathrm{H}), 7.98$ (s, 2H), $7.83(\mathrm{~d}, J=7.0 \mathrm{~Hz}, 4 \mathrm{H}), 7.73(\mathrm{~s}, 2 \mathrm{H}), 7.69$ (t, $J=7.5 \mathrm{~Hz}, 4 \mathrm{H}), 7.66-7.61(\mathrm{~m}, 2 \mathrm{H}), 3.67(\mathrm{t}, J=7.0 \mathrm{~Hz}, 4 \mathrm{H}), 1.68$ (br, 4H), 1.45-1.20 (m, 20H), $0.86(\mathrm{t}, J=6.5 \mathrm{~Hz}, 6 \mathrm{H}) .{ }^{13} \mathrm{C}$ NMR $\left(\mathrm{CDCl}_{3}, 125 \mathrm{MHz}\right): \delta=167.85,150.29,144.83,139.78,136.67$, $136.01,134.77,133.19,129.80,129.34,129.03,128.77,128.72$, $124.86,124.70,123.45,123.33$, 38.41, 31.80, 29.17, 29.15, 28.58, 27.00, 22.59, 13.93. HR MS (EI): calcd for $\mathrm{C}_{56} \mathrm{H}_{52} \mathrm{~N}_{2} \mathrm{O}_{4}\left(\mathrm{M}^{+}\right)$, 816.3927; found, 816.3908 (error: $-2.33 \mathrm{ppm}$ ).

\section{Fabrication and characterization of OFET devices}

Top-contact, bottom-gate TFTs were prepared. A heavily $\mathrm{p}^{+}$doped silicon wafer (100, Silicon Quest International, resistivity $\left.<0.005 \Omega \mathrm{cm}^{-1}\right)$ with $200 \mathrm{~nm}$ thermal silicon dioxide $\left(\mathrm{SiO}_{2}\right)$ was used as the substrate/gate electrode, with the $\mathrm{SiO}_{2}$ layer serving as the gate dielectric. The $\mathrm{SiO}_{2} / \mathrm{Si}$ substrate was cleaned with acetone and isopropanol (IPA). It was then immersed in a piranha solution $\left(\mathrm{V}\left(\mathrm{H}_{2} \mathrm{SO}_{4}\right): \mathrm{V}\left(\mathrm{H}_{2} \mathrm{O}_{2}\right)=2: 1\right)$ for 20 minutes, followed by rinsing with deionized water, and then was re-immersed in 0.1 M OTS or HMDS in anhydrous toluene at $60{ }^{\circ} \mathrm{C}$ for 20 minutes. It was then rinsed with toluene, and then blow-dried with nitrogen gas. The semiconductor layer was deposited on top of the OTS- or HMDS-modified substrates by spin-coating the $1.0 \mathrm{wt} \%$ solution in chloroform, then thermal annealing at selected temperatures for $20 \mathrm{~min}$. Subsequently, gold source/drain electrode pairs were deposited by thermal evaporation through a metal shadow mask to create a series of OFETs with various channel length $(L=100 / 150 \mathrm{~mm})$ and width $(W=1 \mathrm{~mm})$ dimensions. The OFET devices were then characterized using a Keithley SCS- 4200 probe station under $\mathrm{N}_{2}$ conditions in the dark.

\section{Acknowledgements}

G. Dai thanks financial support from China Postdoctoral Science Foundation 2016M590498. C. Chi acknowledges financial support from the MOE Tier 1 grant (R-143-000-573-112), Tier 2 grant (MOE2014-T2-1-080) and Tier 3 programme (MOE2014-T3-1-004).

\section{References}

1 H. Hopf, Angew. Chem., Int. Ed., 2013, 52, 12224.

2 (a) K. Brand, Ber. Dtsch. Chem. Ges., 1912, 45, 3071; (b) W. C. Lothrop, J. Am. Chem. Soc., 1941, 63, 1187; (c) R. F. C. Brown, N. Choi, K. J. Coulston, F. W. Eastwood, U. E. Wiersum and L. W. Jenneskens, Tetrahedron Lett., 1994, 35, 4405; (d) M. Chakraborty, C. A. Tessier and W. J. Youngs, J. Org. Chem., 1999, 64, 2947; (e) M. Saito, M. Nakamura and T. Tajima, Chem. - Eur. J., 2008, 14, 6062; $(f)$ T. Kawase, A. Konishi, Y. Hirao, K. Matsumoto, H. Kurata and T. Kubo, Chem. - Eur. J., 2009, 15, 2653; ( $g$ ) Z. U. Levi and T. D. Tilley, J. Am. Chem. Soc., 2009, 131, 2796; (h) H. Zhang, T. Karasawa, H. Amada, A. Wakamiya and S. Yamaguchi, Org. Lett., 2009, 11, 3076; (i) Z. U. Levi and T. D. Tilley, J. Am. Chem. Soc., 2010, 132, 11012; (j) F. Xu, L. Peng, A. Orita and J. Otera, Org. Lett., 2012, 14, 3970; ( $k$ ) T. Maekawa, Y. Segawa and K. Itami, Chem. Sci., 2013, 4, 2369; (l) H. Li, B. Wei, L. Xu, W.-X. Zhang and Z. Xi, Angew. Chem., Int. Ed., 2013, 52, 10822; $(m)$ C. Chen, M. Harhausen, R. Liedtke, K. Bussmann, A. Fukazawa, S. Yamaguchi, J. L. Petersen, C. D. Daniliuc, R. Fröhlich, G. Kehr and G. Erker, Angew. Chem., Int. Ed., 2013, 52, 5992; (n) J. Zhao, K. Oniwa, N. Asao, Y. Yamamoto and T. Jin, J. Am. Chem. Soc., 2013, 135, 10222; (o) J. Shen, D. Yuan, Y. Qiao, X. Shen, Z. Zhang, Y. Zhong, Y. Yi and X. Zhu, Org. Lett., 2014, 16, 4924; (p) A. Konishi, T. Fujiwara, N. Ogawa, Y. Hirao, K. Matsumoto, H. Kurata, T. Kubo, C. Kitamura and T. Kawase, Chem. Lett., 2010, 39, 300; (q) F. Xu, L. Peng, K. Shinohara, T. Nishida, K. Wakamatsu, M. Uejima, T. Sato, K. Tanaka, N. Machida, H. Akashi, A. Orita and J. Otera, Org. Lett., 2015, 17, 3014; (r) J.-J. Shen, J.-Y. Shao, X. Zhu and Y.-W. Zhong, Org. Lett., 2016, 18, 256.

3 T. Kawase, T. Fujiwara, C. Kitamura, A. Konishi, Y. Hirao, K. Matsumoto, H. Kurata, T. Kubo, S. Shinamura, H. Mori, E. Miyazaki and K. Takimiya, Angew. Chem., Int. Ed., 2010, 49, 7728.

4 (a) G. Dai, J. Chang, W. Zhang, S. Bai, K.-W. Huang, J. Xu and C. Chi, Chem. Commun., 2015, 51, 503; (b) C. Liu, S. Xu, W. Zhu, X. Zhu, W. Hu, Z. Li and Z. Wang, Chem. - Eur. J., 2015, 21, 17016. 
5 (a) M. Nakano, I. Osaka, K. Takimiya and T. Koganezawa, J. Mater. Chem. C, 2014, 2, 64; (b) M. Nakano, I. Osaka and K. Takimiya, J. Mater. Chem. C, 2015, 3, 283; (c) C. Li, C. Liu, Y. Li, X. Zhu and Z. Wang, Chem. Commun., 2015, 51, 693; (d) G. Dai, J. Chang, X. Shi, W. Zhang, B. Zheng, K.-W. Huang and C. Chi, Chem. - Eur. J., 2015, 21, 2019.

6 (a) Q. Zheng, J. Huang, A. Sarjeant and H. E. Katz, J. Am. Chem. Soc., 2008, 130, 14410; (b) J. Shao, J. Chang, G. Dai and C. Chi, J. Polym. Sci., Part A: Polym. Chem., 2014, 52, 2454.

7 (a) D. Shukla, S. F. Nelson, D. C. Freeman, M. Rajeswaran, W. G. Ahearn, D. M. Meyer and J. T. Carey, Chem. Mater., 2008, 20, 7486; (b) J. Chang, Q. Ye, K. W. Huang, J. Zhang, Z. K. Chen, J. Wu and C. Chi, Org. Lett., 2012, 14, 2964; (c) J. Chang, J. Shao, J. Zhang, J. Wu and C. Chi, RSC Adv., 2013, 3, 6775; (d) J. Shao, J. Chang and C. Chi, Chem. - Asian J., 2014, 9, 253; (e) L. Liu, Z. Ren, C. Xiao, B. He, H. Dong, S. Yan, W. Hu and Z. Wang, Chem. Commun., 2016, 52, 4902.

8 (a) R. J. Chesterfield, J. C. McKeen, C. R. Newman, P. C. Ewbank, D. A. Da Silva Filho, J. L. Brédas, L. L. Miller, K. R. Mann and C. D. Frisbie, J. Phys. Chem. B, 2004, 108, 19281; (b) T. Zhang, D. Sun, X. Ren, L. Liu, G. Wen, Z. Ren, H. Li and S. Yan, Soft Matter, 2013, 9, 10739.

9 (a) Z. Wang, C. Kim, A. Facchetti and T. J. Marks, J. Am. Chem. Soc., 2007, 129, 13362; (b) H. Usta, C. Kim, Z. Wang, S. Lu, H. Huang, A. Facchetti and T. J. Marks, J. Mater. Chem., 2012, 22, 4459.

10 (a) Y.-C. Lin, C.-H. Lin, C.-Y. Chen, S.-S. Sun and B. Pal, Org. Biomol. Chem., 2011, 9, 4507; (b) Q. Ye, J. Chang, K. W.
Huang and C. Chi, Org. Lett., 2011, 13, 5960; (c) S. Katsuta, K. Tanaka, Y. Maruya, S. Mori, S. Masuo, T. Okujima, H. Uno, K.-I. Nakayama and H. Yamada, Chem. Commun., 2011, 47, 10112.

11 (a) H. Qu, W. Cui, J. Li, J. Shao and C. Chi, Org. Lett., 2011, 13, 924; (b) J.-J. Chang, H. Qu, Z.-E. Ooi, J. Zhang, Z.-K. Chen, J. Wu and C. Chi, J. Mater. Chem. C, 2013, 1, 456.

12 J. Shao, J. Chang and C. Chi, Org. Biomol. Chem., 2012, 10, 7045.

13 (a) J. Li, J.-J. Chang, H. S. Tan, H. Jiang, X. Chen, Z. Chen, J. Zhang and J. Wu, Chem. Sci., 2012, 3, 846; (b) J. Chang, J. Li, K. L. Chang, J. Zhang and J. Wu, RSC Adv., 2013, 3, 8721.

14 G. Dai, J. Chang, J. Wu and C. Chi, J. Mater. Chem., 2012, 22, 21201.

15 K. M. Psutka, K. J. A. Bozek and K. E. Maly, Org. Lett., 2014, 16, 5442-5445.

16 A. F. Uchoa, K. T. De Oliveira, M. S. Baptista, A. J. Bortoluzzi, Y. Iamamoto and O. A. Serra, J. Org. Chem., 2011, 76, 8824. 17 (a) A. J. Bard and L. R. Faulkner, Electrochemical Methods: Fundamentals and Applications, Wiley, New York, 1984; (b) J. Pommerehne, H. Vestweber, W. Guss, R. F. Mahrt, H. Bassler, M. Porsch and J. Daub, Adv. Mater., 1995, 7, 551; (c) C. Chi and G. Wegner, Macromol. Rapid Commun., 2005, 26, 1532.

18 J. Chang, C. Chi, J. Zhang and J. Wu, Adv. Mater., 2013, 25, 6442.

19 L. Liu, Z. Ren, C. Xiao, H. Dong, S. Yan, W. Hu and Z. Wang, Org. Electron., 2016, 35, 186. 